\title{
Principles and methods for ensuring safe operation of high-rise buildings
}

\author{
Oleg Korol ${ }^{1 *}$ and Yuliya Kustikova ${ }^{1}$ \\ ${ }^{1}$ Moscow State University of Civil Engineering, Yaroslavskoe shosse, 26, Moscow, 129337, Russia
}

\begin{abstract}
The purpose of monitoring the technical condition of high-rise buildings is to prevent possible negative situations leading to significant socio-economic losses by timely warning of the emergence of such situations. To achieve this goal, it is necessary to solve the following main tasks, such as: identifying the time and place of origin and development of negative processes that lead to the emergence of an emergency situation; analysis of the possible development of the situation in time; development of management decisions; formation and submission of warning signals; obtaining new knowledge about the operation of the object, the factors of influence on this object, the speed of development of destructive processes. When solving the above problems, an important role is played by constructing an adequate mathematical model of the object, the parameters of which should be calibrated according to the current monitoring results.
\end{abstract}

\section{Introduction}

Damages and defects in building structures, as practice shows, occur $50 \%$ or more at the construction stage, $20 \%$ at the operational stage and 30\% due to errors in geological research and design. Avoiding these problems will help to monitor the condition of soils, foundations, structures during construction and operation, as well as the use of safety systems.

As for high-rise buildings, security issues are of crucial importance here. Each such building is a complex constructive system with a large number of engineering communications. The increased number of buildings and, consequently, the presence in them of a significant number of people with limited opportunities for their evacuation require the designers to solve additional problems. In particular, the inclusion in the draft measures to prevent, detect and eliminate emergencies, evacuation and rescue people.

\section{Literature review}

Until recently, in the world of construction science, there was a problem of constructing theoretical models and software for project security of buildings and structures, taking into account the degradation of the systemic static and dynamic stability of load-bearing structures caused by thin geodynamic, geological and geophysical and other natural accumulative processes of deferred action [1-7].

\footnotetext{
* Corresponding author: mrkorol.oleg@gmail.com
} 
This problem was particularly acute and contradictory in seismic-passive regions of urbanized territories with bases that, on the one hand, are not affected by accidentally dangerous seismic loads and impacts, and on the other, have a fundamentally heterogeneous thin structure of the geological section that is inconsistent with a rigorous design assessment, down to the depths crystalline basement [8-10].

The results of the measurements show that under the influence of external sources the building performs rather complex resonant oscillations of at least two types - the oscillations of the building as a single system of the "object-base" type and the oscillation of individual elements or parts of the building [11-13].

As a result of the full-scale instrumental studies of geodynamic safety of the responsible building objects, it became clear that the initial cause of the launch of local geodeformation mechanisms is the previously unknown and therefore poorly studied processes of cyclic "fatigue" of base soils, assembly junctions and building materials. In turn, the experimental data obtained and the analytical identification of cause-effect relationships have made it possible to reliably establish microseismic and microgravitational mechanisms for the activation of such phenomena [14].

The obtained statistical and experimental data and identification of resonant cause-effect relationships allowed to establish microseismic and microgravitational mechanisms of activation of such phenomena reliably [15-17].

According to the results of the research it was also established that they are geoecological manifestations of the effect of long-term accumulation of nonlinear effects of technogenic excitation of resonant microseisms in the bases of these objects. Despite the significant difference in the scale and nature of the evolution of cosmic and terrestrial catastrophic processes, they are united by the common physical nature of the gravidynamic cause-effect relations of the launching of dangerous global meteorological, climatic, geophysical, ecological, seismic, geodeformation and other terrestrial processes [18-20].

\section{Methodology}

The main reasons for the collapse of high-rise buildings are:

- exposure to natural factors that lead to aging and corrosion of construction materials and reduce their physico-mechanical characteristics: air environment, atmospheric moisture, groundwater, subsidence ground, negative air temperature, etc;

- natural disasters causing destruction: hurricanes, storms, tornados, tsunamis, floods, earthquakes, landslides, mudflows, snow slips, etc;

- design and production defects of structures and technical systems: errors in exploration and design, poor quality of construction or building materials and structures;

- the impact of technological processes on materials and structures: additional loads, high temperatures, vibrations, oxidants;

- violation of the rules for the operation of structures, technical systems and resulting fires, explosions of fumes of gasoline, chemicals, gas, etc.

The basic principles of monitoring the technical condition include:

- continuity of the monitoring process;

- reliability of the monitoring system;

- reliability of the results;

- the effectiveness of the system.

In practice, in order to consistently comply with the principle of continuity, it is necessary to build systems for monitoring the technical state in such a way as to provide the minimum possible intervals for obtaining information on the characteristics of the object under given 
economic constraints. This is due to the need to comply with the following principle, namely, the principle of reliability.

Table 1. Shows the ways and forms of implementation of these principles.

\begin{tabular}{|l|l|}
\hline \multicolumn{1}{|c|}{ Principle } & \multicolumn{1}{c|}{ Content } \\
\hline $\begin{array}{l}\text { Continuity of the } \\
\text { monitoring process }\end{array}$ & $\begin{array}{l}\text { Organization of a monitoring system for the technical condition of high-rise } \\
\text { buildings and structures in which information about the state of an object or } \\
\text { its elements is recorded at intervals not exceeding the characteristic times of } \\
\text { events associated with the impact on the object or its ability to resist the } \\
\text { impact. }\end{array}$ \\
\hline $\begin{array}{l}\text { Reliability of the } \\
\text { monitoring system }\end{array}$ & $\begin{array}{l}\text { Integrates the reliability of the equipment - and the reliability of determining } \\
\text { the parameters of the impact and resistance to the impact, taking into account } \\
\text { the probabilistic nature of these parameters. Such accounting is extremely } \\
\text { important for the choice of time and amplitude characteristics of the } \\
\text { elements of the monitoring system, including such as temporal resolution, } \\
\text { degree of sampling, dynamic range and the like. }\end{array}$ \\
\hline $\begin{array}{l}\text { Reliability of the } \\
\text { results }\end{array}$ & $\begin{array}{l}\text { The definition of the parameter under consideration by two or more } \\
\text { alternative methods sharply raises the reliability of measurements and the } \\
\text { quality of the monitoring system as a whole. }\end{array}$ \\
\hline $\begin{array}{l}\text { Efficiency of the } \\
\text { system }\end{array}$ & $\begin{array}{l}\text { The ability of the system to register, carry out data transformation and } \\
\text { analysis, and generalize the results obtained to achieve the set goals and } \\
\text { solve the tasks. }\end{array}$ \\
\hline
\end{tabular}

The monitoring system should be designed in such a way as to provide the required probability of registering the process essential for the facility.

A significant number of methods used in the construction of monitoring systems, including methods for determining the stress-strain state, are indirect. At the same time, the result of measurements is influenced by a large number of factors that are difficult to take into account, which reduces the reliability of the results obtained. In this connection, it seems necessary to use methods based on different physical principles for measuring the parameters of a structure, comparing and analyzing the results obtained. Given the high responsibility of high-rise buildings and structures, it is necessary to install several independent monitoring systems for the same physical parameters.

An important aspect of the efficiency principle is the economic aspect. So, for example, when registering changes in the stress-strain state by measuring the relative elongations in concrete, economic costs are sharply reduced with increasing the base of the relative strain sensor. To achieve the same reliability in the case of using sensors with a short base, much more of them are required, as well as the application of mathematical averaging procedures. Similar tasks arise in the design of other monitoring subsystems.

Analysis of the structural features of high-rise buildings allows us to formulate the following proposals for the organization of a monitoring system: (Table 2).

In practice, in order to consistently comply with the principle of continuity, it is necessary to build systems for monitoring the technical state in such a way as to provide the minimum possible intervals for obtaining information on the characteristics of the object under given economic constraints. This is due to the need to comply with the following principle, namely, the principle of reliability. This phenomenon is well studied in mechanical engineering as a multi-cycle and low-cycle fatigue under a constant load cycle. These processes can explain the numerous accidents occurring when there are no significant impacts on the structure. Constant monitoring of the nature of the change in impact allows us to conclude that the degree of damage accumulation, and thus the residual resource of the structure, its reliability. 
Table 2. Methods and methods for providing controlled parameters.

\begin{tabular}{|c|c|}
\hline Controlled measures and parameters & Methods \\
\hline $\begin{array}{l}\text { Integrity control and detection of defects in } \\
\text { foundation slabs and slabs and covering of the } \\
\text { stylobate part of the structure }\end{array}$ & $\begin{array}{l}\text { - acoustic, based on the sensing elements } \\
\text { installed in the body of the plates; } \\
\text { - fiber-optic, based on reflectometry in fiber } \\
\text { optic lightguides, embedded in the body of plates } \\
\text { near their surface }\end{array}$ \\
\hline $\begin{array}{l}\text { Determination of vertical deformations and } \\
\text { bends of the foundation slab, revealing the } \\
\text { unevenness of the draft }\end{array}$ & $\begin{array}{l}\text { - geodetic leveling; } \\
\text { hydrostatic leveling, installation of } \\
\text { inclinometers }\end{array}$ \\
\hline $\begin{array}{l}\text { Measurement of relative strains (stresses) of the } \\
\text { main structural elements, the list of which is } \\
\text { determined on the basis of numerical modeling } \\
\text { and expert evaluation, in comparison with } \\
\text { reinforcement maps. The most likely locations } \\
\text { for the installation of sensors are: slabs of the } \\
\text { stylobate part, support bearing structures of the } \\
\text { hulls, their spans and consoles }\end{array}$ & $\begin{array}{l}\text { - independent strain-gauge systems based on } \\
\text { fiber-optic Bragg sensors (VOD), string and } \\
\text { electromechanical sensors, and also on the basis } \\
\text { of acoustic methods (including acoustic } \\
\text { emission) }\end{array}$ \\
\hline $\begin{array}{l}\text { Reconstruction of spatial spaces of structural } \\
\text { elements of a structure }\end{array}$ & $\begin{array}{l}\text { - measurements by means of a complex of } \\
\text { robotic total stations; } \\
\text { - digital photogrammetry; } \\
\text { - laser scanning }\end{array}$ \\
\hline $\begin{array}{l}\text { Observation of the amplitude-frequency } \\
\text { characteristics of elements and structures of a } \\
\text { structure }\end{array}$ & $\begin{array}{l}\text { - installation of triaxial accelerometers in } \\
\text { controlled areas of the facility, installation of } \\
\text { seismometers }\end{array}$ \\
\hline $\begin{array}{l}\text { Climatic observations, including temperature } \\
\text { and humidity, wind and snow loads }\end{array}$ & - methods and means of climate control \\
\hline $\begin{array}{l}\text { Situational monitoring of parameters } \\
\text { determined on the basis of development of } \\
\text { scenarios of adverse impacts and events in their } \\
\text { probable aggregate }\end{array}$ & $\begin{array}{l}\text { - all of the above methods applied to the design } \\
\text { zones defined by scenarios developed on the } \\
\text { basis of interdisciplinary expert assessments }\end{array}$ \\
\hline
\end{tabular}

Taking into account that the parameters of the reliability of construction objects depend to a large extent on the geodynamic stability of the object-foundation systems, the solution of the safety problem begins with a pre-project geotechnical justification for the stability of the fine structure of the geological section of the bases, followed by their own geodynamic resonances, geodeformation and geoecological risks at the design stage and concludes with regular monitoring of the evolution of the banks and sediment of buildings and structures during the construction period operation and maintenance.

According to the results of the research it was also found that, especially in megacities, unexpected super-project geodesic information bases of engineering structures and communications are in fact geological manifestations of the effect of long-term accumulation of non-linear consequences of technogenic microcyclic excitation of vibroseis in the zone of laying or placement of these objects. In other words, there is a technogenic violation or acceleration of the natural evolution of geological and hydrogeological processes in base soils, i.e. according to already established terminology there is a technogenic violation of natural geoecological conditions in the zone of construction sites, and especially in the territories of megacities and areas of mass development.

The latter statement is due to the fact that it is megacities that are distinguished by increased technogenic vibroseismic activity, as well as heterogeneity of the fine structure of the geological section and uneven static and dynamic load in the distributed "object-base" system, which significantly enhances the geoecological efficiency of natural and technogenic 
microseisms on the grounds of the calculated volume grounds and the building object as a whole.

Thus, it can be concluded that if in geospatial zones the geodynamic stability of geological bases of building objects is disturbed by earthquakes, then in seismic-active zones - by ultralow-frequency geodeformation processes responsible for the latent long-term accumulation of hydrogeological and physicomechanical inhomogeneities in geological sections.

However, geo-information processes under the foundations of building objects and engineering structures in seismic-passive regions can be significantly strengthened or "accelerated" as a result of natural and technogenic excitation of vibroseismic and gravisseismic resonances of objects and their geological bases.

The work on designing and creating a monitoring system is carried out in several stages (Fig. 1.).

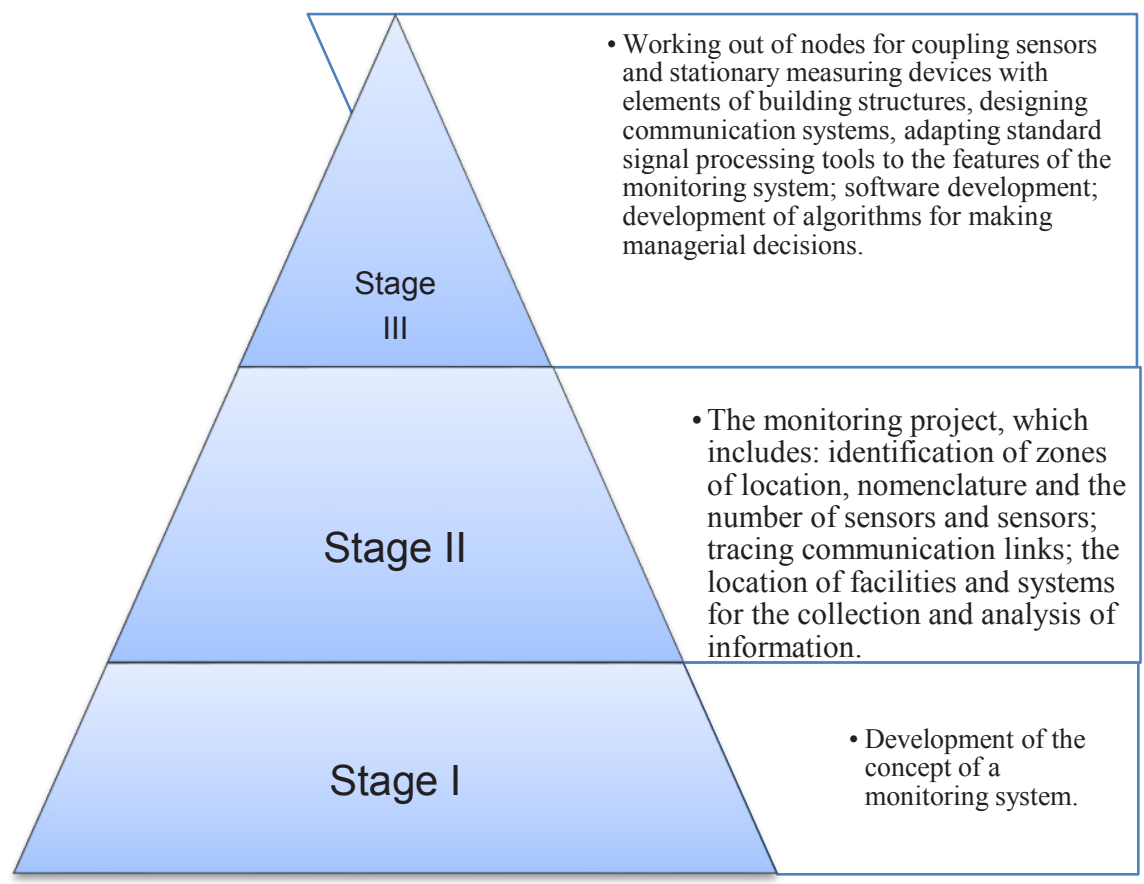

Fig. 1. Stages of development of the monitoring system.

It should be noted that the installation of sensors of the monitoring system should be carried out at the earliest possible stages of construction as the structure is erected. This requirement is extremely important, as it provides information on the "zero" loading of the structure and allows you to track the change in the parameters of structures at all stages of construction, assessing their compliance with design values.

However, the progressive development of the building science, along with new advances in the field of information technology, allows us to successfully overcome a number of such limitations. Among them, in the first place, we should mention essentially new results of research and development in recent years in the field of project modeling and monitoring of the dynamic stress-strain state of essentially heterogeneous bases of building objects [3]. These works open up new possibilities for project modeling of cause and effect relationships for the implementation of previously poorly studied phenomena and the effects of a difficultly controlled smooth decrease in the stability of object-base type systems and longterm operational reliability of building objects throughout their life cycle. 
To assess the various types of monitoring of buildings from the point of view of the most effective solution, their multicriteria analysis was carried out. The following were chosen as the main criteria:

$\mathrm{C}_{1}$ - the range of diversity of structural elements and the building as a whole

$\mathrm{C}_{2}$ - is the latitude of the spectrum of the measured parameters

$\mathrm{C}_{3}$ - accuracy of measurements of specified parameters

$\mathrm{C}_{4}$ - real-time range

$\mathrm{C}_{5}$ - speed of monitoring the current state of structural elements (and buildings)

$\mathrm{C}_{6}$ - the complexity of installing the system

$\mathrm{C}_{7}$ - level of automation of the monitoring process

$\mathrm{C}_{8}$ - minimization of investment and operating costs

The monitoring methods discussed above are ranked taking into account the integrated assessment of the monitored parameters for ensuring the complex safety of high-rise buildings.

Table 3. Ranking of methods for monitoring high-rise buildings.

\begin{tabular}{|l|l|c|}
\hline \multicolumn{2}{|c|}{ Types of monitoring } & Rank of importance \\
\hline$M_{1}$ & Monitoring of the state of objects by point sensors & 4 \\
\hline$M_{2}$ & Georadiolocation & 3 \\
\hline$M_{3}$ & Fiber-optic monitoring & 1 \\
\hline$M_{4}$ & Geophysical monitoring & 2 \\
\hline
\end{tabular}

We determine the coefficient of importance by the formula:

$$
C_{M n}=\frac{2(n-i+1)}{n(n+1)} \cdot 100
$$

Table 4. Matrix of paired comparisons of criteria by measures.

\begin{tabular}{|l|l|l|l|}
\hline$\Omega_{1,1}=1$ & $\Omega_{1,2}=0,5$ & $\Omega_{1,3}=0,25$ & $\Omega_{1,4}=0,3$ \\
\hline$\Omega_{2,1}=2$ & $\Omega_{2,2}=1$ & $\Omega_{2,3}=0,5$ & $\Omega_{2,4}=0,6$ \\
\hline$\Omega_{3,1}=4$ & $\Omega_{3,2}=2$ & $\Omega_{3,3}=1$ & $\Omega_{3,4}=1,3$ \\
\hline$\Omega_{4,1}=3$ & $\Omega_{4,2}=1,5$ & $\Omega_{4,3}=0,75$ & $\Omega_{4,4}=1$ \\
\hline
\end{tabular}

$$
N_{i}=\left(\Omega_{1.1} \times \Omega_{1.2} \times \Omega_{1.3}\right)^{1 / 3}
$$

Then we normalize the numbers obtained by the formula:

$$
\alpha_{i}=N_{i} \sum N_{i} n_{i}=1
$$

Table 5. Ranking of evaluation criteria for types of monitoring.

\begin{tabular}{|c|c|c|c|c|}
\hline \multirow{2}{*}{ Criteria } & \multicolumn{4}{|c|}{$\begin{array}{c}\text { Ranks / Indicators of importance by type of } \\
\text { monitoring }\end{array}$} \\
\cline { 2 - 5 } & $\mathrm{M}_{1}$ & $\mathrm{M}_{2}$ & $\mathrm{M}_{3}$ & $\mathrm{M}_{4}$ \\
\hline $\mathrm{C}_{1}$ & $4 / 10$ & $3 / 20$ & $2 / 30$ & $1 / 40$ \\
\hline $\mathrm{C}_{2}$ & $3 / 20$ & $4 / 10$ & $1 / 40$ & $2 / 30$ \\
\hline $\mathrm{C}_{3}$ & $3 / 20$ & $4 / 10$ & $1 / 40$ & $2 / 30$ \\
\hline $\mathrm{C}_{4}$ & $4 / 10$ & $2 / 30$ & $1 / 40$ & $3 / 20$ \\
\hline $\mathrm{C}_{5}$ & $4 / 20$ & $3 / 10$ & $2 / 30$ & $1 / 40$ \\
\hline $\mathrm{C}_{6}$ & $4 / 10$ & $3 / 20$ & $1 / 40$ & $2 / 30$ \\
\hline $\mathrm{C}_{7}$ & $4 / 10$ & $3 / 20$ & $1 / 40$ & $2 / 30$ \\
\hline $\mathrm{C}_{8}$ & $1 / 40$ & $3 / 20$ & $2 / 30$ & $3 / 20$ \\
\hline
\end{tabular}


Table 6. Matrix of paired comparisons of criteria by types of monitoring and priority vectors.

\begin{tabular}{|c|c|c|c|c|c|c|c|c|c|}
\hline & & & trix of pai & red compa & isons & & & $\begin{array}{l}\text { Vectors } \\
\text { of priorities }\end{array}$ & $\begin{array}{l}\text { Normali } \\
\text { zation }\end{array}$ \\
\hline & & & & Ever & $\mathrm{M}_{1}$ & & & & \\
\hline$\Omega_{1,1}=1$ & $\Omega_{1,2}=0,5$ & $\Omega_{1,3}=0,5$ & $\Omega_{1,4}=1$ & $\Omega_{1,5}=0,5$ & $\Omega_{1,6}=1$ & $\Omega_{1,7}=1$ & $\Omega_{1,8}=0,25$ & 1,548 & 0,111 \\
\hline$\Omega_{2,1}=2$ & $\Omega_{2,2}=1$ & $\Omega_{2,3}=1$ & $\Omega_{2,4}=2$ & $\Omega_{2,5}=1$ & $\Omega_{2,6}=2$ & $\Omega_{2,7}=2$ & $\Omega_{2,8}=0,5$ & 1,842 & 0,132 \\
\hline$\Omega_{3,1}=2$ & $\Omega_{3,2}=1$ & $\Omega_{3,3}=1$ & $\Omega_{3,4}=2$ & $\Omega_{3,5}=1$ & $\Omega_{3,6}=2$ & $\Omega_{3,7}=2$ & $\Omega_{3,8}=0,5$ & 1,842 & 0,132 \\
\hline$\Omega_{4,1}=1$ & $\Omega_{4,2}=0,5$ & $\Omega_{4,3}=0,5$ & $\Omega_{4,4}=1$ & $\Omega_{4,5}=0,5$ & $\Omega_{4,6}=1$ & $\Omega_{4,7}=1$ & $\Omega_{4,8}=0,25$ & 1,548 & 0,111 \\
\hline$\Omega_{5,1}=2$ & $\Omega_{5,2}=1$ & $\Omega_{5,3}=1$ & $\Omega_{5,4}=2$ & $\Omega_{5,5}=1$ & $\Omega_{5,6}=2$ & $\Omega_{5,7}=2$ & $\Omega_{5,8}=0,5$ & 1,842 & 0,132 \\
\hline$\Omega_{6,1}=1$ & $\Omega_{6,2}=0,5$ & $\Omega_{6,3}=0,5$ & $\Omega_{6,4}=1$ & $\Omega_{6,5}=0,5$ & $\Omega_{6,6}=1$ & $\Omega_{6,7}=1$ & $\Omega_{6,8}=0,25$ & 1,548 & 0,111 \\
\hline$\Omega_{7,1}=1$ & $\Omega_{7,2}=0,5$ & $\Omega_{7,3}=0,5$ & $\Omega_{7,4}=1$ & $\Omega_{7,5}=0,5$ & $\Omega_{7,6}=1$ & $\Omega_{7,7}=1$ & $\Omega_{7,8}=0,25$ & 1,548 & 0,111 \\
\hline$\Omega_{8,1}=4$ & $\Omega_{8,2}=2$ & $\Omega_{8,3}=2$ & $\Omega_{8,4}=4$ & $\Omega_{8,5}=2$ & $\Omega_{8,6}=4$ & $\Omega_{8,7}=4$ & $\Omega_{8,8}=1$ & 2,190 & 0,157 \\
\hline & & & & Ever & $\mathrm{M}_{2}$ & & & & \\
\hline$\Omega_{1,1}=1$ & $\Omega_{1,2}=2$ & $\Omega_{1,3}=2$ & $\Omega_{1,4}=0,7$ & $\Omega_{1,5}=2$ & $\Omega_{1,6}=1$ & $\Omega_{1,7}=1$ & $\Omega_{1,8}=1$ & 1,345 & 0,128 \\
\hline$\Omega_{2,1}=0,5$ & $\Omega_{2,2}=1$ & $\Omega_{2,3}=1$ & $\Omega_{2,4}=0,3$ & $\Omega_{2,5}=1$ & $\Omega_{2,6}=0,5$ & $\Omega_{2,7}=0,5$ & $\Omega_{2,8}=0,5$ & 1,232 & 0,117 \\
\hline$\Omega_{3,1}=0,5$ & $\Omega_{3,2}=1$ & $\Omega_{3,3}=1$ & $\Omega_{3,4}=0,3$ & $\Omega_{3,5}=1$ & $\Omega_{3,6}=0,5$ & $\Omega_{3,7}=0,5$ & $\Omega_{3,8}=0,5$ & 1,232 & 0,117 \\
\hline$\Omega_{4,1}=1,5$ & $\Omega_{4,2}=3$ & $\Omega_{4,3}=3$ & $\Omega_{4,4}=1$ & $\Omega_{4,5}=3$ & $\Omega_{4,6}=1,5$ & $\Omega_{4,7}=1,5$ & $\Omega_{4,8}=1,5$ & 1,414 & 0,135 \\
\hline$\Omega_{5,1}=0,5$ & $\Omega_{5,2}=1$ & $\Omega_{5,3}=1$ & $\Omega_{5,4}=0,3$ & $\Omega_{5,5}=1$ & $\Omega_{5,6}=0,5$ & $\Omega_{5,7}=0,5$ & $\Omega_{5,8}=0,5$ & 1,232 & 0,117 \\
\hline$\Omega_{6,1}=1$ & $\Omega_{6,2}=2$ & $\Omega_{6,3}=2$ & $\Omega_{6,4}=0,7$ & $\Omega_{6,5}=2$ & $\Omega_{6,6}=1$ & $\Omega_{6,7}=1$ & $\Omega_{6,8}=1$ & 1,345 & 0,128 \\
\hline$\Omega_{7,1}=1$ & $\Omega_{7,2}=2$ & $\Omega_{7,3}=2$ & $\Omega_{7,4}=0,7$ & $\Omega_{7,5}=2$ & $\Omega_{7,6}=1$ & $\Omega_{7,7}=1$ & $\Omega_{7,8}=1$ & 1,345 & 0,128 \\
\hline$\Omega_{8,1}=1$ & $\Omega_{8,2}=2$ & $\Omega_{8,3}=2$ & $\Omega_{8,4}=0,7$ & $\Omega_{8,5}=2$ & $\Omega_{8,6}=1$ & $\Omega_{8,7}=1$ & $\Omega_{8,8}=1$ & 1,345 & 0,128 \\
\hline & & & & Ever & $\mathrm{M}_{3}$ & & & & \\
\hline$\Omega_{1,1}=1$ & $\Omega_{1,2}=0,75$ & $\Omega_{1,3}=0,75$ & $\Omega_{1,4}=0,75$ & $\Omega_{1,5}=1$ & $\Omega_{1,6}=0,75$ & $\Omega_{1,7}=0,75$ & $\Omega_{1,8}=1$ & 1,612 & 0,141 \\
\hline$\Omega_{2,1}=1,3$ & $\Omega_{2,2}=1$ & $\Omega_{2,3}=1$ & $\Omega_{2,4}=1$ & $\Omega_{2,5}=1,3$ & $\Omega_{2,6}=1$ & $\Omega_{2,7}=1$ & $\Omega_{2,8}=1,3$ & 1,314 & 0,115 \\
\hline$\Omega_{3,1}=1,3$ & $\Omega_{3,2}=1$ & $\Omega_{3,3}=1$ & $\Omega_{3,4}=1$ & $\Omega_{3,5}=1,3$ & $\Omega_{3,6}=1$ & $\Omega_{3,7}=1$ & $\Omega_{3,8}=1,3$ & 1,314 & 0,115 \\
\hline$\Omega_{4,1}=1,3$ & $\Omega_{4,2}=1$ & $\Omega_{4,3}=1$ & $\Omega_{4,4}=1$ & $\Omega_{4,5}=1,3$ & $\Omega_{4,6}=1$ & $\Omega_{4,7}=1$ & $\Omega_{4,8}=1,3$ & 1,314 & 0,115 \\
\hline$\Omega_{5,1}=1$ & $\Omega_{5,2}=0,75$ & $\Omega_{5,3}=0,75$ & $\Omega_{5,4}=0,75$ & $\Omega_{5,5}=1$ & $\Omega_{5,6}=0,75$ & $\Omega_{5,7}=0,75$ & $\Omega_{5,8}=1$ & 1,612 & 0,141 \\
\hline$\Omega_{6,1}=1,3$ & $\Omega_{6,2}=1$ & $\Omega_{6,3}=1$ & $\Omega_{6,4}=1$ & $\Omega_{6,5}=1,3$ & $\Omega_{6,6}=1$ & $\Omega_{6,7}=1$ & $\Omega_{6,8}=1,3$ & 1,314 & 0,115 \\
\hline$\Omega_{7,1}=1,3$ & $\Omega_{7,2}=1$ & $\Omega_{7,3}=1$ & $\Omega_{7,4}=1$ & $\Omega_{7,5}=1,3$ & $\Omega_{7,6}=1$ & $\Omega_{7,7}=1$ & $\Omega_{7,8}=1,3$ & 1,314 & 0,115 \\
\hline$\Omega_{8,1}=1$ & $\Omega_{8,2}=0,75$ & $\Omega_{8,3}=0,75$ & $\Omega_{8,4}=0,75$ & $\Omega_{8,5}=1$ & $\Omega_{8,6}=0,75$ & $\Omega_{8,7}=0,75$ & $\Omega_{8,8}=1$ & 1,612 & 0,141 \\
\hline & & & & Ever & $\mathrm{M}_{4}$ & & & & \\
\hline$\Omega_{1,1}=1$ & $\Omega_{1,2}=1,3$ & $\Omega_{1,3}=1,3$ & $\Omega_{1,4}=2$ & $\Omega_{1,5}=1$ & $\Omega_{1,6}=1,3$ & $\Omega_{1,7}=1,3$ & $\Omega_{1,8}=2$ & 1,352 & 0,130 \\
\hline$\Omega_{2,1}=0,75$ & $\Omega_{2,2}=1$ & $\Omega_{2,3}=1$ & $\Omega_{2,4}=1,5$ & $\Omega_{2,5}=0,75$ & $\Omega_{2,6}=1$ & $\Omega_{2,7}=1$ & $\Omega_{2,8}=1,5$ & 1,307 & 0,125 \\
\hline$\Omega_{3,1}=0,75$ & $\Omega_{3,2}=1$ & $\Omega_{3,3}=1$ & $\Omega_{3,4}=1,5$ & $\Omega_{3,5}=0,75$ & $\Omega_{3,6}=1$ & $\Omega_{3,7}=1$ & $\Omega_{3,8}=1,5$ & 1,307 & 0,125 \\
\hline$\Omega_{4,1}=0,5$ & $\Omega_{4,2}=0,7$ & $\Omega_{4,3}=0,7$ & $\Omega_{4,4}=1$ & $\Omega_{4,5}=0,5$ & $\Omega_{4,6}=0,7$ & $\Omega_{4,7}=0,7$ & $\Omega_{4,8}=1$ & 1,246 & 0,119 \\
\hline$\Omega_{5,1}=1$ & $\Omega_{5,2}=1,3$ & $\Omega_{5,3}=1,3$ & $\Omega_{5,4}=2$ & $\Omega_{5,5}=1$ & $\Omega_{5,6}=1,3$ & $\Omega_{5,7}=1,3$ & $\Omega_{5,8}=2$ & 1,352 & 0,130 \\
\hline$\Omega_{6,1}=0,75$ & $\Omega_{6,2}=1$ & $\Omega_{6,3}=1$ & $\Omega_{6,4}=1,5$ & $\Omega_{6,5}=0,75$ & $\Omega_{6,6}=1$ & $\Omega_{6,7}=1$ & $\Omega_{6,8}=1,5$ & 1,307 & 0,125 \\
\hline$\Omega_{7,1}=0,75$ & $\Omega_{7,2}=1$ & $\Omega_{7,3}=1$ & $\Omega_{7,4}=1,5$ & $\Omega_{7,5}=0,75$ & $\Omega_{7,6}=1$ & $\Omega_{7,7}=1$ & $\Omega_{7,8}=1,5$ & 1,307 & 0,125 \\
\hline$\Omega_{8,1}=0,5$ & $\Omega_{8,2}=0,7$ & $\Omega_{8,3}=0,7$ & $\Omega_{8,4}=1$ & $\Omega_{8,5}=0,5$ & $\Omega_{8,6}=0,7$ & $\Omega_{8,7}=0,7$ & $\Omega_{8,8}=1$ & 1,246 & 0,119 \\
\hline
\end{tabular}


Table 7. Baseline data for assessing the significance of the criteria.

\begin{tabular}{|c|c|c|c|c|c|c|c|c|c|}
\hline \multirow{2}{*}{$\begin{array}{c}\text { Significance of } \\
\text { events }\end{array}$} & \multicolumn{9}{|c|}{ Significance of evaluation criteria } \\
\cline { 2 - 10 } & $\mathrm{C}_{1}$ & $\mathrm{C}_{2}$ & $\mathrm{C}_{3}$ & $\mathrm{C}_{4}$ & $\mathrm{C}_{5}$ & $\mathrm{C}_{6}$ & $\mathrm{C}_{7}$ & $\mathrm{C}_{8}$ \\
\hline $\mathrm{M}_{1}$ & $\alpha_{1}=0,200$ & $\alpha_{1 \mathrm{M} 1}=0,111$ & $\alpha_{2 \mathrm{M} 1}=0,132$ & $\alpha_{3 \mathrm{M} 1}=0,132$ & $\alpha_{4 \mathrm{M} 1}=0,111$ & $\alpha_{5 \mathrm{M} 1}=0,132$ & $\alpha_{6 \mathrm{M} 1}=0,111$ & $\alpha_{7 \mathrm{M} 1}=0,111$ & $\alpha_{8 \mathrm{M} 1}=0,157$ \\
\hline $\mathrm{M}_{2}$ & $\alpha_{2}=0,175$ & $\alpha_{1 \mathrm{M} 2}=0,128$ & $\alpha_{2 \mathrm{M} 2}=0,117$ & $\alpha_{3 \mathrm{M} 2}=0,117$ & $\alpha_{4 \mathrm{M} 2}=0,135$ & $\alpha_{5 \mathrm{M} 2}=0,117$ & $\alpha_{6 \mathrm{M} 2}=0,128$ & $\alpha_{7 \mathrm{M} 2}=0,128$ & $\alpha_{8 \mathrm{M} 2}=0,128$ \\
\hline $\mathrm{M}_{3}$ & $\alpha_{3}=0,356$ & $\alpha_{1 \mathrm{M} 3}=0,141$ & $\alpha_{3 \mathrm{M} 3}=0,115$ & $\alpha_{3 \mathrm{M} 3}=0,115$ & $\alpha_{4 \mathrm{M} 3}=0,115$ & $\alpha_{5 \mathrm{M} 3}=0,141$ & $\alpha_{6 \mathrm{M} 3}=0,115$ & $\alpha_{7 \mathrm{M} 3}=0,115$ & $\alpha_{8 \mathrm{M} 3}=0,141$ \\
\hline $\mathrm{M}_{4}$ & $\alpha_{4}=0,269$ & $\alpha_{1 \mathrm{M} 4}=0,130$ & $\alpha_{4 \mathrm{M} 4}=0,125$ & $\alpha_{3 \mathrm{M} 4}=0,125$ & $\alpha_{4 \mathrm{M} 4}=0,119$ & $\alpha_{5 \mathrm{M} 4}=0,130$ & $\alpha_{6 \mathrm{M} 4}=0,125$ & $\alpha_{7 \mathrm{M} 4}=0,125$ & $\alpha_{8 \mathrm{M} 4}=0,119$ \\
\hline
\end{tabular}

We will evaluate the significance of the criteria for all the developed measures.

Criterion $\mathrm{C}_{1}: 0,200 \times 0,111+0,175 \times 0,128+0,356 \times 0,141+0,269 \times 0,130=0,130$

Criterion $\mathrm{C}_{2}$ : $0,200 \times 0,132+0,175 \times 0,117+0,356 \times 0,115+0,269 \times 0,125=0,121$

Criterion C3: $0,200 \times 0,132+0,175 \times 0,117+0,356 \times 0,115+0,269 \times 0,125=0,121$

Criterion C4: $0,200 \times 0,111+0,175 \times 0,135+0,356 \times 0,115+0,269 \times 0,119=0,119$

Criterion $\mathrm{C}_{5}: 0,200 \times 0,132+0,175 \times 0,117+0,356 \times 0,141+0,269 \times 0,130=0,132$

Criterion $\mathrm{C}_{6}: 0,200 \times 0,111+0,175 \times 0,128+0,356 \times 0,115+0,269 \times 0,125=0,119$

Criterion $\mathrm{C}_{7}: 0,200 \times 0,111+0,175 \times 0,128+0,356 \times 0,115+0,269 \times 0,125=0,119$

Criterion $\mathrm{C}_{8}: 0,200 \times 0,157+0,175 \times 0,128+0,356 \times 0,141+0,269 \times 0,119=0,136$

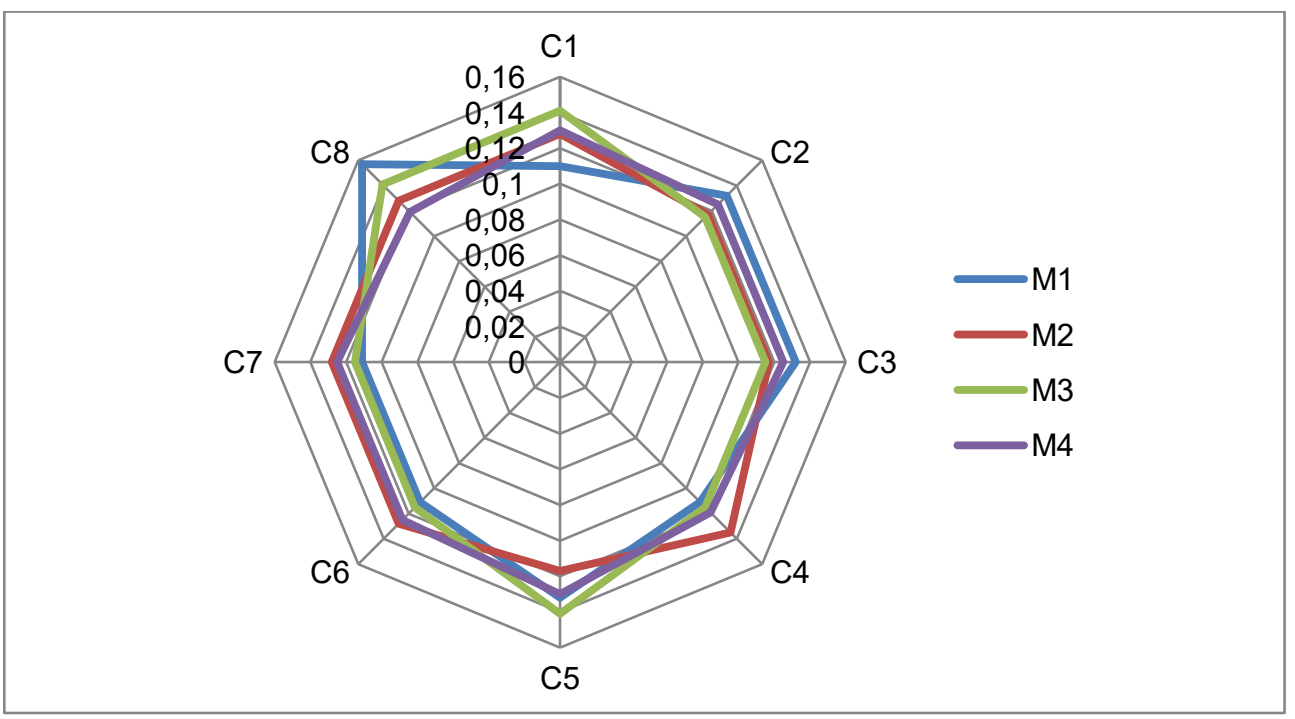

Fig. 2. Indicators of the importance of evaluation criteria for monitoring tall buildings.

The above monitoring systems will allow to track the integral indicators of the state of individual elements and structures in general. On the basis of integral indicators, it is possible to make timely managerial decisions: on calling specialists and conducting instrumental surveys of certain structural elements, making changes to the design decisions at the construction stage, limiting operational loads, evacuating personnel, prohibiting access to certain areas and the like.

Given the high responsibility of high-rise buildings and structures (significant material and human losses in the event of an emergency, and even more so when the structure is destroyed), several independent monitoring systems should be installed for the same physical parameters, i.e. organization of a multi-loop or complex monitoring system. 
In particular, the following actual private tasks of intellectual monitoring were solved:

- predictive automated analysis of the evolution of geodynamic characteristics and resonances of object-base type systems;

- Assessment of the effect of seismoacoustic and physicomechanical inhomogeneities in the calculated volume of grounds on the accelerated degradation of geodynamic stability of systems of the "object-base" type of high-rise buildings and structures;

- Assessment of the impact of geodynamic resonances of buildings and structures on the growth of risks of stability loss of the fine structure of the geological section in the estimated base volume;

- Evaluation of the long-term impact of microcircular gravis-seismic loads on the risks of uneven sediment in high-rise buildings and structures and the degradation of their systemic stability.

\section{Conclusion}

1. Existing technical solutions and principles of monitoring the state of building structures are intended mainly for monitoring linear characteristics, vibroseismic loads and transfer functions of buildings and structures. At the same time, the processes of weakening and the dynamic characteristics that reflect them are fundamentally nonlinear in their physical essence.

2. The "linear" approach to solving the problem of controlling the evolution of the residual resource of stability and reliability of buildings and structures allows modeling linear dynamic properties of building structures.

3. Widely distributed calculation software for interpreting monitoring data based on various modifications of the "finite element" method are correct in applying only quasistatic stability for design simulation, but they do not have the necessary mathematical sufficiency for calculating and predicting the modeling of nonlinear processes representing the physical nature of the wear processes and the degradation of the safety of building materials, continuously distributed stiffness's and masses is difficult constructed mechanical oscillation systems.

4. The results of theoretical and field studies of domestic and foreign scientists, including specialists in the field of engineering geophysics, confirm the presence of infra-lowfrequency and high-quality geodynamic resonances of high-rise buildings and structures. Reliable control over the non-linear evolution of parameters requires a significant expansion and tightening of the requirements for instrumental-methodical monitoring tools, including on the frequency band and dynamic error in the infra-low-frequency range of dynamic loads.

\section{References}

1. Zh.G. Mogilyuk, S.I. Zavalishin, M.S. Khlystunov, Scientific review, 7-1, 241-244 (2014)

2. Zh.G. Mogilyuk, M.S. Khlystunov, V.I. Prokopiev, International Journal for Computational Civil and Structural Engineering, 10(2), 120-129 (2014)

3. S.I. Zavalishin, Zh.G. Mogilyuk, M.S. Khlystunov, Scientific review, 7, 245-248 (2014)

4. S.I. Zavalishin, M.S. Khlystunov, Zh.G. Mogilyuk, Ecology of urbanized territories, 4, 35-41 (2015)

5. V.V. Poduvaltsev, M.S. Khlystunov, Zh.G. Mogilyuk, Safety in the technosphere, 3(2), 14-17 (2014) 
6. V.I. Prokopiev, M.S. Khlystunov, Zh.G. Mogilyuk, International Journal for Computational Civil and Structural Engineering, 2, 105-110 (2014)

7. M.S. Khlystunov, V.I. Prokopiev, Zh.G. Mogilyuk, Procedia Engineering, 111, 672 (2015)

8. M.S. Khlystunov, Zh.G. Mogilyuk, Safety of buildings, 3, 16 (2003)

9. Zh.G. Mogilyuk, M.S. Khlystunov, V.I. Prokopiev, Procedia Engineering, 111, 672 678 (2015)

10. V.I. Prokopiev, M.S. Khlystunov, Zh.G. Mogilyuk, Procedia Engineering, 111, 666 671 (2015)

11. S.I. Zavalishin, Zh.G. Mogilyuk, M.S. Khlystunov, Ecology of urbanized territories, 2, 45-50 (2006)

12. Zh.G. Mogilyuk, M.S. Khlystunov, Scientific review, 13, 90-93 (2015)

13. V.V. Poduval'tsev, M.S. Khlystunov, Zh.G. Mogilyuk, Safety in the technosphere, 26 (45), 33-37 (2013)

14. V.I. Telichenko, E.A. Korol, M.S. Khlystunov, High-rise buildings, 1, 5-7 (2008)

15. M.S. Khlystunov, V.I. Prokopiev, Zh.G. Mogilyuk, Procedia Engineering, 111, 297 $301(2015)$

16. M.S. Khlystunov, Zh.G. Mogilyuk, V.V. Poduval'tsev, Measurement Techniques, 58 10, 1139-1143 (2016)

17. V.I. Prokopiev, M.S. Khlystunov, Zh.G. Mogilyuk, Procedia Engineering, 111, 672 678 (2015)

18. E.A. Korol, I.V. Rubtsov, A.V. Kukhta, N.P. Chetverik, High-rise buildings, 5, 123 125 (2008)

19. V.I. Telichenko, E.A. Korol, P.B, S.V. Komissarov, S.G. Arutyunov, A.A. Afanasiev, Management of programs and projects for the erection of high-rise buildings: Scientific publication. (Moscow: ASV Publishing House, 2010)

20. V.I. Telichenko, M.S. Khlystunov, V.I. Prokopiev, Zh.G. Mogilyuk, Ecology of urbanized territories, 2, 13-21 (2011) 